\title{
INTRODUCTION TO THE SYMPOSIUM ON THE ANTHROPOLOGY OF INTERNATIONAL LAW
}

\begin{abstract}
Annelise Riles*
What contributions can anthropology and ethnographic methods make to the study and practice of international law? How might anthropologists and international lawyers work together to address international challenges such as climate change, migration, violence and peace-building? The five essays that follow, each from leading scholars in the field, provide differing and complementary answers to this question.

The discipline of anthropology in its current form is a relatively new discipline, a child of the twentieth century. It is an empirical social science dedicated to discovering specifics about social practices (or, in the American tradition, cultural practices) rather than speaking in abstractions or generalities. In this vein, Rachel Sieder from the Center for Research and Graduate Studies in Social Anthropology in Mexico City argues in her essay that the contribution of anthropologists is "culturally grounded, context-specific, community-based" analysis. ${ }^{1}$ Galit Sarfaty from the University of British Columbia likewise argues that anthropology offers an understanding of "micro-level detail by which international law operates." 2 Early in the twentieth century, anthropologists limited themselves to the study of so-called "small scale societies" or "primitive societies." By mid-century, however, the anthropologist's subject could equally be communities at home, and interactions between "ordinary people" and "the legal system" soon became the bread and butter of a nascent subfield of legal anthropology. By the end of the twentieth century, this work had extended beyond the study of municipal law to international legal institutions, such that anthropological scholarship about international legal institutions and practices is now a robust and vibrant field. ${ }^{3}$

Although this focus on specifics is important, what most distinguishes anthropology is its method—ethnography. The method is prone to exotic fantasies of estrangement from all that is familiar-as in the writings of the self-styled archetypal ethnographer Bronislaw Malinowski, ${ }^{4}$ who wrote poetically of pitching his tent among Trobriand Islanders as the boat that had brought him to that remote island disappeared into the sunset, not to return for a year or more. Yet on a more mundane level, a commitment to long-term engagement with the people one studies, to collaboration on their terms-participating in the community one seeks to understand while studying it—remains central.

The ethnographic study of international legal institutions can mean attendance at UN conferences as an observer, work as an intern with an international agency, or participation in a social movement, all the while

\footnotetext{
* Executive Director, Northwestern Buffett Institute for Global Affairs, Associate Provost for Global Affairs, Professor of Law and Professor (by courtesy) of Anthropology, Northwestern University, Evanston, Illinois, United States.

${ }^{1}$ Rachel Sieder, Anthropological Contributions to International Legal Approaches to Violence Against Indigenous Women, 115 AJIL UNBOUND 272 (2021).

${ }^{2}$ Galit A. Sarfaty, Corporate Actors as Translators in Transnational Lawmaking, 115 AJIL Unbound 278 (2021).

3 See, e.g., Ronald Niezen \& Maria Sapignoli eds., Palaces of Hope: The Anthropology of Global Organizations (2017).

${ }^{4}$ See, e.g., Bronislaw Malinowski, Crime and Custom in Savage Society (1926); Bronislaw Malinowski, Argonauts of the Western Pacific: An Account of Native Enterprise and Adventure in the Archipelagoes of Melanesian New Guinea (1922).
}

(C) Annelise Riles 2021. This is an Open Access article, distributed under the terms of the Creative Commons Attribution licence (http://creativecommons.org/licenses/by/4.0/), which permits unrestricted re-use, distribution, and reproduction in any medium, 
conducting interviews and collecting documents and records. But what matters most of all about this research is the attitude with which the anthropologist approaches it. The anthropologist will try in earnest to learn about and later theorize the subject as it is experienced by her interlocutors, who have their own frameworks, categories, and concerns. She will ask herself what international law looks like when one begins with these categories or concerns rather than with the frameworks of given academic debates. The reasoning here is inductive rather than deductive and phenomenological. The anthropologist Roy Wagner has stated that anthropologists set themselves up for "culture shock" and use this culture shock as an engine of insight about the taken-for-granted givens of dominant frameworks and debates. ${ }^{5}$

As Miia Halme-Tuomisaari from Lund University points out, this work has had relatively little impact on international legal scholarship. ${ }^{6}$ Traditional scholarship remains largely unaware of the anthropology of international law, while critical international legal scholars, she argues, often dip into anthropological writings searching for material to support their own internal theoretical claims in ways that are often antithetical to anthropologists' understandings. Within international institutions, there is nevertheless increasingly a role for experts in "applied anthropology"-field workers in the service of the bureaucratic apparatus who can report on human rights abuses, nutrition levels, tribal conflicts, and so on; who provide "the facts" to the international lawyers' "law"; and who document problems for international law to solve.

Yet as Mark Goodale from the University of Lausanne points out in his essay, both international lawyers and the community of anthropologists who surround them now find themselves at an interesting juncture. ${ }^{7}$ Goodale argues that while in the late twentieth and early twenty-first centuries international legal institutions were takenfor-granted as powerful and significant, they increasingly are viewed by publics as obsolete side-shows to the real political drama happening in the streets. Goodale argues that this creates a quandary for anthropologists of international law, who have made a handy living out of serving as critics of international law, pointing out its lacunae, its injustices and its contradictions. But their critiques matter only insofar as international law matters. Goodale argues that the future of the anthropology of international law, therefore, is in doubt. It may trend toward the study of what he calls international law's "afterlife"- - movements such as the global Black Lives Matter movement, or towards the study of the history of international law. Or the anthropology of international law may disappear altogether. Interestingly, Halme-Tuomisaari disputes this diagnosis of international law's demise from the point of view of her own ethnography among UN monitoring committees. The participants in these committees, she reports, have little sense of malaise about the importance or future of international law. Yet I take Goodale's analysis as a provocation for us to clear the decks and to ask ourselves in earnest what kind of exchange might be imaginable between the disciplines.

We could begin with Halme-Tuomisaari, who of the authors in this special issue is perhaps most deeply engaged with critical international legal theory. ${ }^{8}$ Halme-Tuomisaari opens her essay with an important empirical point often overlooked by anthropologists: there are many different kinds of international lawyers, and the nature and purpose of the discipline are deeply contested. In particular, Halme-Tuomisaari notes a sharp divide between those for whom building up international law and solving global problems is a key commitment and those for whom that project is precisely the problem - the divide between progressivism and critique. For Halme-Tuomisaari, an ethnographic stance becomes a third possibility, an alternative to the false choice between being a booster and a critic of international law. By entering the worlds of both the boosters and the critics as a participant observer,

\footnotetext{
${ }^{5}$ Roy Wagner, The Invention of Culture (1975).

${ }^{6}$ Miia Halme-Tuomisaari, Toward Rejuvenated Inspiration with the Unbearable Lightness of Anthropology, 115 AJIL UnBOUND 283 (2021).

${ }^{7}$ Mark Goodale, After International Law: Anthropology Beyond the "Age of Human Rights", 115 AJIL UnBound 289 (2021).

${ }^{8}$ Miia Halme-Tuomisaari, supra note 6.
} 
full of wonder about what might be encapsulated in these positions, Halme-Tuomisaari finds an orthogonal position from which to see new possibilities.

Taken together, moreover, these essays suggest that anthropological work highlights many new subjects and themes for international law. First, this work brings attention to what is "outside" international law. Sieder, for example, highlights the efforts of indigenous women to combat domestic violence and shows how the frameworks and paradigms of the international legal regime are in fact alienating and counter-productive from their point of view. ${ }^{9}$ This view of international law from the point of view of the people it is meant to serve provides an important critical perspective on what is left out of the international legal regime. It also offers a larger empirical corrective: international law often operates with a highly abstract and unexamined set of assumptions about how the work translates into social change "at the local level." Understanding the points of disconnect with international law's "outside" is therefore critical to its refinement and reconstruction.

Anthropological work also offers equally important insights into the "inside" of international law-what Goodale calls the "juristocracy," that is, elite international law enthusiasts. Halme-Tuomisaari refers to the "sameness" that is shared among the community of UN participants. I have written about the aesthetics of international legal proceedings shared by insiders, for example, and about the techniques and technicalities that these insiders deploy. ${ }^{10}$ Sarfaty likewise writes of shared technologies of governance. All of these practices may be so taken-forgranted by international lawyers that they go largely unnoticed and unanalyzed.

The essays also point to a third contribution-documenting and analyzing emergent practices of international law. They point to new categories of actors and governance regimes that are still insufficiently appreciated in international legal theory, such as global supply chains as a new institutional and governance structure far beyond the nation-state system or quasi-legal rule-making bodies to decide on questions such as freedom of speech online. ${ }^{11}$ Both Sarfaty and Sapignoli demonstrate how corporate techniques of governance, evidence collection, and consensus-building have migrated over to the realm of traditional international institutions, where they are increasingly embraced as new and better ways of doing things.

Another example of this emergent international law is the influence of artificial intelligence within the European Union and at the United Nations, as studied by Sapignoli. ${ }^{12}$ What Sapignoli aptly terms "the social life of the AI system" is still poorly understood by international lawyers. Sapignoli’s ethnography helps us to appreciate the frameworks of the new cadre of experts streaming into international legal circles, their hopes, fantasies, and fears, how these frameworks travel globally, the source of their rhetorical authority, and their impact on the lives of those governed by them. She shows how international actors find new hope in these technologies as ways to overcome all of the doubts and double binds of international governance.

But beyond all these contributions, the essays point to something more, perhaps beyond the register of knowledge and empirics altogether. As Goodale suggests, in these turbulent times, new possibilities are emerging and old ways of doing international law are fading away. As we return to first principles, to achieve the fundamental purpose of sustainable peace and justice, we might begin to rethink the very nature of transnational collaboration itself. Are UN-style negotiations among state representatives - complete with all of the two-step dances to avoid thorny questions of legitimacy in the absence of state consent documented by Halme-Tuomisaari-really the best way? How can we imagine new forms of conversation that no longer subsume citizens, civil society groups, corporations or universities, under the legal fiction of state representation?

\footnotetext{
${ }^{9}$ Sieder, supra note 1.

${ }^{10}$ Annelise Riles, The Network Inside Out (2001).

${ }^{11}$ Sarfaty, supra note 2; Maria Sapignoli, Anthropology and the AI-Turn in Global Governance, 115 AJIL UnBound 294 (2021).

12 Sapignoli, supra note 11.
} 
Here I want to suggest that anthropologists step up as experts in collaboration and translation across differences of all kinds. For example, Sieder's essay is not in fact a "study of" indigenous women's movements to end domestic violence, but rather a report on a collaboration between anthropologists (including herself) and indigenous women, across differences of culture, class, and citizenship, to do this work. Sapignoli, likewise, insists that anthropologists, and all social scientists, are already part of the picture and hence must position themselves as collaborators and not just as observers. If the new genius is a collaborative genius, anthropology is ultimately a project of curating collaboration, born out of a faith that people and their positions are far more multifaceted, confusing, and creative than our best theories can possibly account for. Anthropologists' mid-level analysis of international law, drawing on local categories and translating these into conversation with given academic debates, can, I believe, help us to find the inchoate but already existing threads that constitute a different international legal tapestry.

In this moment of change and reimagination, therefore, the most interesting contribution of anthropology may be its longstanding methodological commitments and experience - the curiosity and willingness to listen, to take time to look sideways, and the skill in hearing and giving voice to the unexpected connections. In this work, anthropology becomes not just a source of data about the world or a source of problems for international law to solve but the foundation of a new international legal method itself. 